\title{
VIRTUAL LEARNING ENVIRONMENT FOR OPEN ONLINE LEARNING
}

\author{
Estela Daukšienè, Margarita Teresevičienè, Airina Volungevičienè, Vytautas Magnus \\ University, Lithuania
}

\section{Summary}

Digital networked society is learning in various platforms, in different ways and at selected time and pace. What are the preferences of members of digital and networked society for the learning platforms? What resources should be used to better fulfil nowadays learner expectations? And how higher education institutions are preparing for that? These are the main research questions of this research. In order to answer the research questions, the theory analysis and quantitative research were performed. The results of the research findings of the preferred learning ways and requirements for virtual learning platform of the online learners who speak Lithuanian are discussed in the paper.

\section{Introduction}

Open educational resources and open online courses and already not a new practice in higher education institutions. However, opening online courses for the society is more common in open universities, while traditional face-to-face learning universities focus more on bended learning approach and usually stay closed, mainly due to limited offer of open online courses. The use of virtual learning environment in university studies is also a common practice, but what features characterize open online learning environment - the virtual environment of $21^{\text {st }}$ century learning of digital and networked society?

As Newman and Scurry (2001) say, learning environment, based on online technologies helps society to be more educated, because students can gain access to a huge amount of information, including schemes, graphics, pictures and videos. Virtual learning environment for open learning first of all has to be open to ensure the easy way to reach the curriculum.

"Many of today's online learning environments are private. This privacy is the consequence of institutional decisions that have resulted in the closing of learning environments to all but those who have officially enrolled in an institution or course. While many of these decisions are logical from an administrative standpoint, educators interested in making learning opportunities available to the masses may have a different perspective." (Mentor; 2007; p.1) 
Grant (2007) has indicated 10 dimensions of online life learning environment which may be grouped to 2 broad ones - Administration and Pedagogical dimensions where the later includes knowledge discovery, analysis, application, management; communication, collaboration, content delivery and evaluation of learner performance.

The use of different tools for learning can be limited if an environment is closed. The use of digital technology various in different learning generations, so the learning environment must be adapted to their needs. $\mathrm{Wu}, \mathrm{Yu}$, and Wang (2018) suggest that different interests of learners should be noted and analysed for the platform to better respond to learner preferences. Andone et al., (2007) suggest learning environment should contain

"a blend of Internet and mobile technologies which enhance student-tutor and
student-student communication through multiple media channels, providing
responsiveness, customizability and flexibility to adapt and be adapted to the
students' needs". (Andone et al., 2007; p.41)

A lot of approaches have been used when discussing and exploring modelling of open learning environment. It could be based on learning style (Fasihuddin, Skinner, \& Athauda, 2017), collaboration (Barbosa, Barbosa, \& Rabello, 2016; Tissenbaum, Berland, \& Lyons, 2017), issues related concepts and skills, collaborative problem-solving opportunities, motivation of learners and context of learning (Lubin \& Ge, 2012) or designed to establish personalized learning (Rahimi, van den Berg, \& Veen, 2015). When analysing professional learners, it was found necessity to rely on aggregation of theory and practice (Milligan \& Littlejohn, 2014) and to create learning environment taking to account learning needs, background, motivations.

Summarizing the theoretical findings on the features of open online learning environment the following categories were noted - easy accessible and stimulating learning, creating a community for communication and collaboration, and pedagogically well organized.

\section{Research methodology}

The aim of the research is to characterize open online learning environment in order to meet the digital and networked society needs. The case of Lithuania was selected for the research, focusing on the needs of digital and learning society for open online learning environment. The used survey method was mixed - combining online survey and face-to-face survey.

In order to construct survey questionnaire, the theory analysis was implemented. The questionnaire was developed, approved and used for a statistically representative survey of adult population $18-65$ in Lithuania in 2018 , by the research team. The research questionnaire involved demographical questions and questions about their preferences for online learning and open resources, use of social networks for learning, their approach to online learning, and features of the virtual learning environment that are important. As the research focus is on the open online learning environment features, this article analyses and focuses only on questions which are related to virtual learning environment. 


\section{Data collection and research participants}

The quantitative research was performed in two ways: (a) the electronic version of questionnaire survey, which was put into Openstudies portal of Vytautas Magnus University and (b) direct surveying at the respondent's home using multivariate stratified sampling, which was performed with the help of one of the Lithuanian market and opinion research centre. The total number of respondents, who qualitied for the digital and networked society description, was 1241 . The main criterion to quality for the digital and networked society was the use of internet.

The research was performed from March to October, 2018. The research participants were Lithuanians, aged 18-74, living in Lithuania or abroad; mainly situated in cities with more than 10,000 residents ( $68 \%$ of respondents). There were $45 \%$ men and $55 \%$ women out of 1241 respondents. Research participants' distribution by age was fairly even - $19 \%$ were of 18 $24,19 \%$ were of $25-34,18 \%$ were of $35-44,20 \%$ were of $45-54,16 \%$ were of $55-64$, with exception of persons aged over 65 , who represented only $8 \%$ of all respondents. Therefore, for more even distribution, respondents in the research analysis were grouped into 4 groups: up to 27 years; $28-38$ years; $39-52$ years and more than 53 years. Research participants were mostly full-time employees (57\%), holding a degree of tertiary education (59\%), with a wide range of professions, representing social care, police, agriculture, education, administration, maintaining, industry, management, or services, with the largest part (14.5\%) of sales managers.

\section{Data analysis}

Online survey and face-to-face survey data merged for statistical analyses using MS Excel and SPSS (Statistical Package for Social Sciences) 23 version. The descriptive statistics and crosstabs were used for data analyses in the initial data analysis phase, which results are presented here. The more in-depth factorial analysis and modelling will be performed in the next research phase. The analysis took place from October 2018 to January 2019. The research findings will be presented in research workshop.

\section{Research findings}

Digital and networked society representatives are interested in online study programs (78\%), and they prefer flexibility in choosing separate courses to study (82\%) or studying in courses for professional development (76\%). They think that connections to video conferences or viewing lecture recordings would seem engaging too (73\%). About $70 \%$ of respondents indicated that they prefer the use of mobile devices in learning.

The most preferable ways of learning of survey respondents were indicated- distance learning course with a teacher (their consultations and lectures) and short video tutorials or lectures with interactive tests (see Figure 1) 


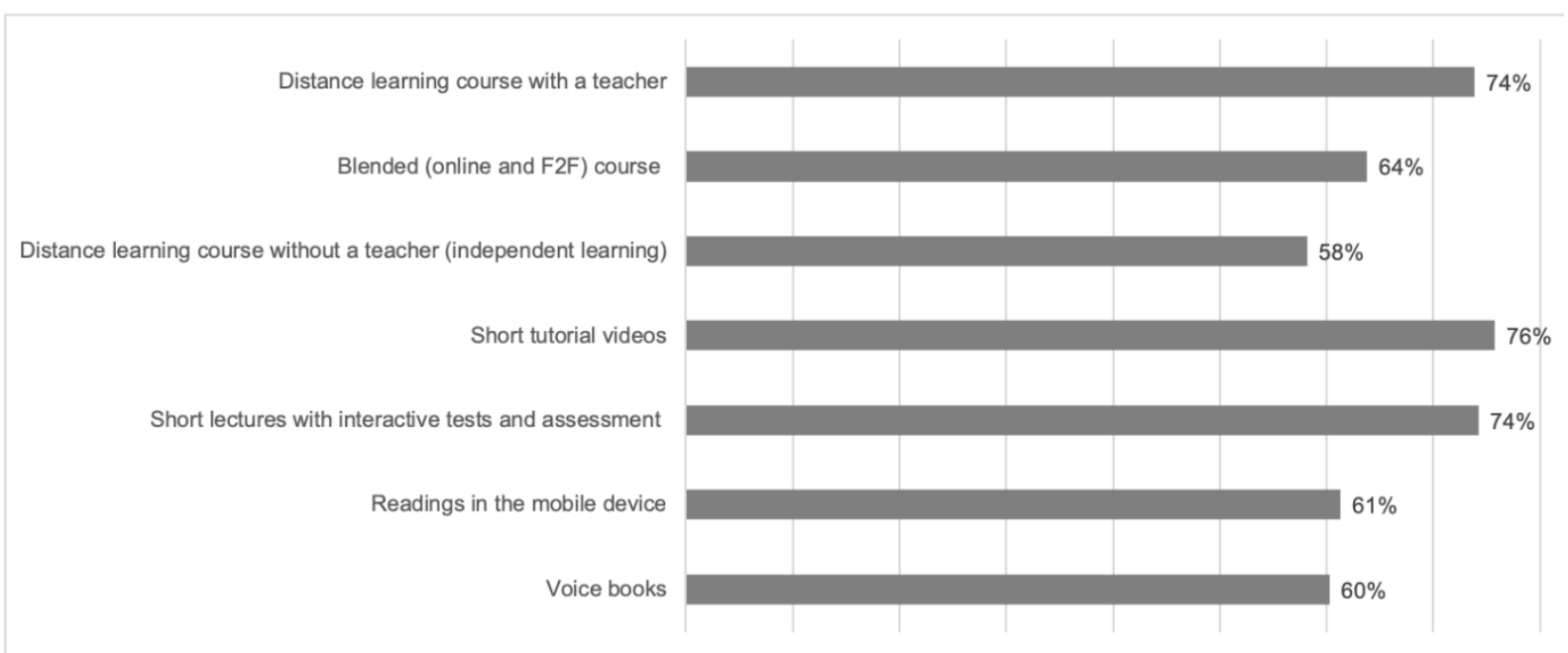

Figure 1. Learner preferences for online learning

The most preferable feature for learning online was studying at a suitable pace and time, which was indicated by $84-87 \%$ of the survey respondents. Among the most stimulating factors for online learning were also a possibility to combine learning with the work and family (74\%).

The most preferable features of open online learning environment are the possibility to plan the time, to be able to access learning materials, and a possibility to communicate and collaborate with learners and teacher (indicated by $89-79 \%$ of respondents, see Figure 2). Among least preferred environment features were the reception of badges, synchronized with virtual learning environment - in total only 38\% of all respondents preferred this functionality. However, after the in depth analysis it was noted that $86 \%$ of the youngest representatives (18-24 years old) would prefer such a functionality.

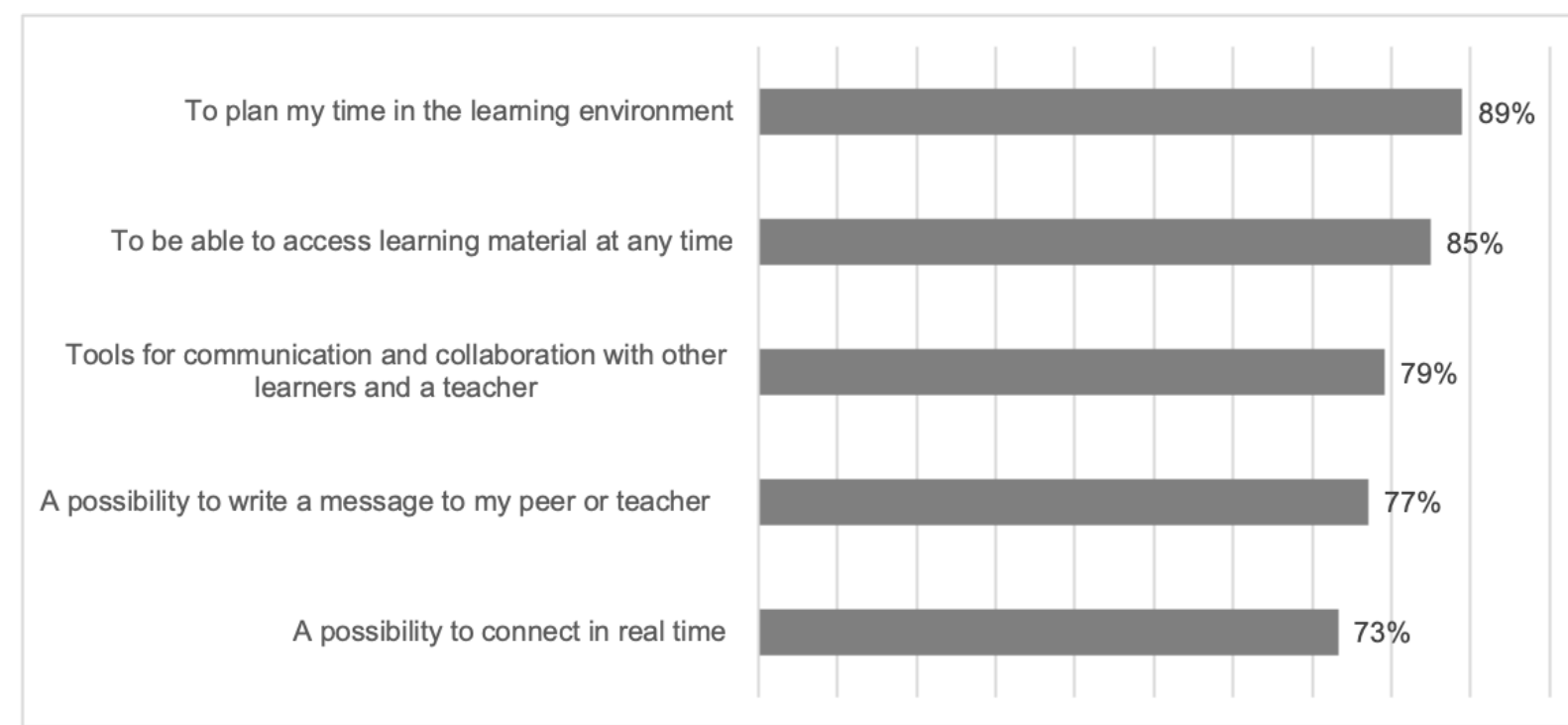

Figure 2. The most preferable open online learning environment features from technical and social perspective

"A possibility to write a message" is more important for younger adult groups - $80 \%$ of the 18-52 years old respondents prefer this and $67 \%$ of the 53 year and older respondents. This 
could be explained with the with decreasing senior participation in training and learning activities, less social networking. The importance "to connect in real time" also decreases with age: $79 \%$ of young adults would like to do that; $76 \%$ in age group $28-38,73 \%$ in age group 39 -52 and $65 \%$ in the group of more than 53 years old respondents.

From the pedagogical point of view the respondents also indicated some preferences for learning organization and learning content delivery $-84 \%$ prefer learning content presented in different forms - written, video and audio; $80 \%$ prefer open educational resources (readings and video recordings) to be used, 78\% would like learning material to be presented in small chunks and having clear instructions for learning; and 75\% would appreciate periodic feedback about the learning progress and achievements.

Practical application of the research findings and insights are integrated in Vytautas Magnus University Open studies platform (openstudies.vdu.lt), which focus on providing the university online courses for the community, not just the university students. The courses are prepared for group learning or learning individually, with teacher consultations.

The theoretical considerations of the paper and further empirical research will be complemented in the further stages of a four-year research project "Open Online Learning for Digital and Networked Society (3.3-LMT-K-712-01-0189)". Project is funded by the European Social Fund according to the activity "Improvement of researchers" qualification by implementing world-class R\&D projects’ of Measure No. 09.3.3-LMT-K-712.

\section{References}

Andone, D., Dron, J., Pemberton, L., \& Boyne, C. (2007). E-Learning Environments for Digitally-Minded Students. Journal of Interactive Learning Research, 18(1), 41-53.

Barbosa, J., Barbosa, D., \& Rabello, S. (2016). A Collaborative Model for Ubiquitous Learning Environments. International Journal on E-Learning, 15(1), 5-25.

Fasihuddin, H., Skinner, G., \& Athauda, R. (2017). Towards Adaptive Open Learning Environments: Evaluating the Precision of Identifying Learning Styles by Tracking Learners' Behaviours. Education and Information Technologies, 22(3), 807-825.

Lubin, I., \& Ge, X. (2012). Investigating the influences of a LEAPS model on preservice teachers' problem solving, metacognition, and motivation in an educational technology course. Educational Technology Research \& Development, 60(2), 239-270. doi:10.1007/s11423-011-9224-3

Mentor, K. (2007). Open Access Learning Environments. Online Journal of Distance Learning Administration, 10(1). Retrieved from https://www.westga.edu/ distance/ojdla/spring101/mentor101.htm

Milligan, C., \& Littlejohn, A. (2014). Supporting Professional Learning in a Massive Open Online Course. International Review of Research in Open and Distance Learning, 15(5), 197-213. 
Newman, F., \& Scurry, J. (2001, July 13). Online technology pushes pedagogy to the forefront. Chronicle of Higher Education. Chronicle [Blog post]. Retrieved from http://chronicle.com/weekly/v47/i44/44b00701.htm

Rahimi, E., van den Berg, J., \& Veen, W. (2015). A Learning Model for Enhancing the Student's Control in Educational Process Using Web 2.0 Personal Learning Environments. British Journal of Educational Technology, 46(4), 780-792.

Tissenbaum, M., Berland, M., \& Lyons, L. (2017). DCLM Framework: Understanding Collaboration in Open-Ended Tabletop Learning Environments. International Journal of Computer-Supported Collaborative Learning, 12(1), 35-64.

Wu, P., Yu, S., \& Wang, D. (2018). Using a Learner-Topic Model for Mining Learner Interests in Open Learning Environments. Educational Technology \& Society, 21(2), 192-204. 